\title{
DÜBLIN
}

Technological University Dublin

ARROW@TU Dublin

\section{Strain distribution in the porcine lumbar laminae under asymmetric loading}

\author{
Colin Bright \\ Technological University Dublin, colin.bright@tudublin.ie \\ Stephen Tiernan \\ Technological University Dublin, stephen.tiernan@tudublin.ie \\ Fiona McEvoy \\ Technological University Dublin, fiona.mcevoy@tudublin.ie
}

See next page for additional authors

Follow this and additional works at: https://arrow.tudublin.ie/ittengcon

Part of the Engineering Commons, and the Medicine and Health Sciences Commons

\section{Recommended Citation}

Bright, C., Tiernan, S., McEvoy, F., \& Kiely, P. (2017). Strain distribution in the porcine lumbar laminae under asymmetric loading. Proceedings of the Institution of Mechanical Engineers, Part H: Journal of Engineering in Medicine, 231(10), 945-951. https://doi.org/10.1177/0954411917719744

This Conference Paper is brought to you for free and open access by the School of Engineering at ARROW@TU Dublin. It has been accepted for inclusion in Conference Papers by an authorized administrator of ARROW@TU Dublin. For more information, please contact arrow.admin@tudublin.ie, aisling.coyne@tudublin.ie, gerard.connolly@tudublin.ie.

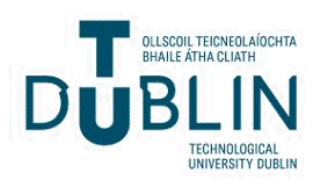


Authors

Colin Bright, Stephen Tiernan, Fiona McEvoy, and Patrick Kiely

This conference paper is available at ARROW@TU Dublin: https://arrow.tudublin.ie/ittengcon/13 


\title{
Strain distribution in the porcine lumbar laminae under asymmetric loading
}

Proc IMechE Part H:

$\mathrm{J}$ Engineering in Medicine

20I7, Vol. 23I (I0) 945-95I

(c) IMechE 2017

Reprints and permissions:

sagepub.co.uk/journalsPermissions.nav DOI: 10.1 I77/09544|19177/9744

journals.sagepub.com/home/pih

(SAGE

\author{
Colin Bright', Stephen Tiernan', Fiona McEvoy' and Patrick Kiely²
}

\begin{abstract}
If the articular facets of the vertebra grow in an asymmetric manner, the developed geometry causes an asymmetry of loading. When the loading environment is altered by way of increased activity, the likelihood of acquiring a stress fracture may be increased. The combination of geometric asymmetry and increased activity is hypothesised to be the precursor to the stress fracture under investigation in this study, spondylolysis. This vertebral defect is an acquired fracture with $7 \%$ prevalence in the paediatric population. This value increases to $21 \%$ among athletes who participate in hyperextension sports. Tests were carried out on porcine lumbar vertebrae, on which the effect of facet angle asymmetry was simulated by offsetting the load laterally by $7 \mathrm{~mm}$ from the mid-point. The aim of the study is to investigate whether an increase in the coronal orientation of one facet leads to an increase in strain in the corresponding vertebral lamina. Strain in the laminae was recorded using six 3-element stacked rosette strain gauges placed bilaterally. Results show that a significant linear predictive relationship exists between load offset and average strain level in the vertebral laminae with $p$ values of 0.006 and 0.045 for principal strains $\varepsilon_{1}$ and $\varepsilon_{2}$ on the right-hand side, and $p$-values of 0.009 and 0.001 for principal strains $\varepsilon_{1}$ and $\varepsilon_{2}$ on the left-hand side $\left(R^{2}\right.$ all $\left.>0.9\right)$. This study concludes that facet angle asymmetry does lead to a difference in strain in the vertebral laminae. Change in principal strain as a result of facet asymmetry has a linear relationship and an asymmetry threshold exists beyond which compressive strain on the more coronally oriented facet can be increased by up to $15 \%$.
\end{abstract}

\section{Keywords}

Spondylolysis, facet tropism, facet angle asymmetry, pars interarticularis, lumbar laminae, strain, strain gauge, finite element analysis, Hueter-Volkmann, scoliosis

Date received: I3 February 20I7; accepted: I3 June 2017

\section{Introduction}

Vertebral stress fractures in otherwise healthy, athletic adolescents are a well-documented problem. ${ }^{1-4}$ The neural arch of the lumbar vertebrae, specifically the portion between the articular facets, the pars interarticularis, has a high incidence of fracture. Stress fractures in this region are given the clinical name spondylolysis. This vertebral defect is an acquired fracture with a $7 \%$ prevalence in the paediatric $(<18$ years old $)$ population; ${ }^{1}$ however, this number increases in the athletically active population with a prevalence of up to $11 \%$ of female gymnasts, ${ }^{5} 10.5 \%$ of Swedish athletes ${ }^{6}$ and $10.7 \%$ of Canadian gymnasts ( $>10$ years old). ${ }^{7}$ It can occur unilaterally which ordinarily leads to healing, or bilaterally, which in chronic cases can lead to an established non-union and grade 1 or 2 spondylolisthesis (anterior displacement of the vertebral body) ${ }^{8,9}$ and vertebral wedging which some authors attribute to mechanisms governed by the Hueter-Volkmann law. ${ }^{10,11}$ The fracture occurs at the lowest lumbar level in $90 \%$ of cases and many patients with spondylolysis will develop significant lumbar complications in later life. ${ }^{12}$ While a considerable volume of work exists on the links between athletic technique and spondylolysis, ${ }^{13-15}$ particularly among athletes who participate in hyperextension sports where a prevalence of $21 \%$ of spondylolysis has been recorded, ${ }^{16}$ the role of the underlying bony anatomy remains unclear.

\footnotetext{
'Institute of Technology Tallaght, Dublin, Ireland

${ }^{2}$ Our Lady's Children's Hospital, Dublin, Ireland
}

\section{Corresponding author:}

Colin Bright, Institute of Technology Tallaght, Tallaght, Dublin 24, Ireland. Email: Colin.Bright@ittdublin.ie 
The pars interarticularis fits Currey's ${ }^{17}$ description of a 'sandwich' bone, that is, a pair of cortices comprising cortical bone bearing the bending load with trabecular filling maintaining the space between them, thus keeping the second moment of area large. This bending force created by extension of the spine in the sagittal plane is transmitted to the pars interarticularis via the facet joints. The force inducing this bending is applied perpendicular to the principal axis of the dorsal cortex of the pars, on a plane which is $30^{\circ}$ from the mid-plane of the intervertebral disc (Figure 1). In this plane, the extensor force can be divided between the left and right hand facet joints. If one of these facet joints is more coronally oriented, the portion of extensor force on that side will be increased, thus the force acting in the posterior direction on that side will be greater than the less coronally oriented side.

The use of bonded resistance strain gauges is a wellestablished method of strain measurement ${ }^{18,19}$ and is still considered the 'gold standard'. ${ }^{20}$ To date, only a moderate amount of attention has been given to the measurement of strain in the posterior portions of the vertebrae. The most significant work done to date is that of Shah et al. ${ }^{21}$ where function spinal units (FSU) from human cadavers were fitted with rosette strain gauges and loaded in tension and compression. The authors measured strain on the ventral and dorsal surfaces of the pars interarticularis at a compressive load of $1472 \mathrm{~N}$ applied to the entire FSU which resulted in a dominance of tensile principal strain on the ventral surface of the pars, and compressive principal strain on the dorsal surface, indicating that the pars interarticularis itself is undergoing bending. Recorded values for compressive principal strain on the dorsal surface were between 2400 and $2450 \mu \varepsilon$. Another significant study is that of Szivek et al.,22 where in vivo strains on lower thoracic vertebral laminae, with biologically bonded strain gauges, were examined. The authors reported maximum strains in the vertebral laminae during twisting. Values from 495 to $1450 \mu \varepsilon$ were reported over a period of weeks, increasing as the calcium phosphatecoated gauges became fully bonded to the bone surface. The highest laminae strain values were reported during stair climbing at $1795 \mu \varepsilon$. Kuo and Wang ${ }^{23}$ in a study of porcine pars interarticularis strains during swaying motions stated that strains were highest $(\leqslant 1700 \mu \varepsilon)$ during motions in the posterior and posterolateral directions (extensions of the spine with twisting). This lends support to the hypothesis that like the physical motion of twisting, the asymmetric bony anatomy causes twisting, and the strains on one side of the pars interarticularis are increased. Bone tissue is known to respond differently depending on strain level. The strain level and local strain history dictate the cellular response. ${ }^{24}$ The expected strains in this study should fall close to or below the pathological level $(<3000 \mu \varepsilon){ }^{25}$

It is clear from the increase in prevalence of spondylolysis, between the normal paediatric population and those that are athletically active, that the fracture has a

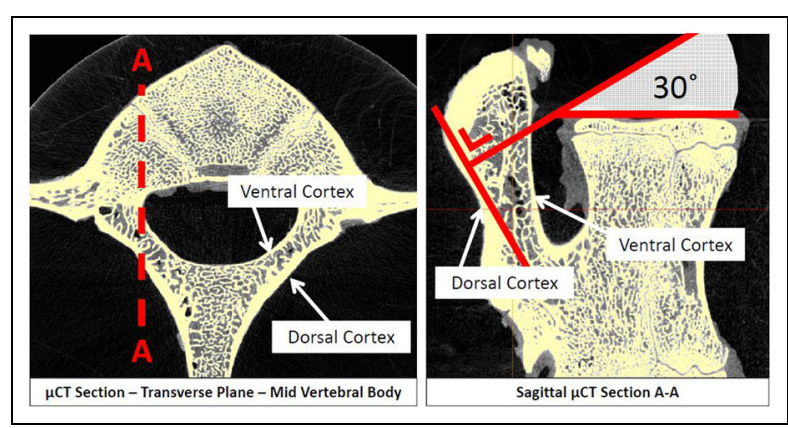

Figure I. Micro-CT section through a porcine vertebra showing the ventral and dorsal cortices separated by cancellous bone.

mechanical aetiology. Furthermore, individuals with one facet joint more coronally oriented than the other have been shown to be predisposed to unilateral spondylolysis. ${ }^{9,12,26}$ What is unclear is to what degree this difference in coronal orientation affects the likelihood of acquiring the spondylolysis stress fracture.

The hypothesis that is being tested is that individuals with a more coronally oriented facet have an increased likelihood of spondylolysis because there is increased strain on the bone supporting that facet. A specimen that is likely to fracture is defined as one that equals or exceeds known pathological strain levels for bone tissue. This hypothesis will be investigated by loading the facet joints of porcine vertebrae in an asymmetric manner thus simulating a difference in coronal orientation and recording the resulting strains in the pars interarticularis.

\section{Materials and methods}

\section{Specimens}

For this study, porcine lumbar vertebrae were selected: the fourth and fifth lumbar vertebra from seven different animals (6 months old), 13 specimens in total (1 excluded due to damage). The vertebrae were dissected of all soft tissue including the facet surface cartilage, then cleaned using a scalpel and vertebral body endplates were left intact. The laminae surfaces were prepared for the fitting of strain gauges by cleaning with sandpaper (grade 400) and degreasing using Vishay GC-6 isopropyl alcohol. Three TML $45^{\circ} / 90^{\circ}$ threeelement stacked rosette gauges $(\varnothing 4.5 \mathrm{~mm})$ were fitted on each side of the vertebral lamina, six in total (Figure 2(c)). The gauges were fitted using cyanoacrylate adhesive (TML). Strain data were recorded using National Instruments LabView C-Daq data acquisition hardware and a custom-built NI LabView virtual instrument. Six rosettes giving 18 channels of strain data were recorded. A single vertebra was set aside for micro-computed tomographic (CT) scanning before the strain gauges were fitted (Figure 1).

A mould was manufactured to cast a specimen fixation material (polyurethane resin) around the two 


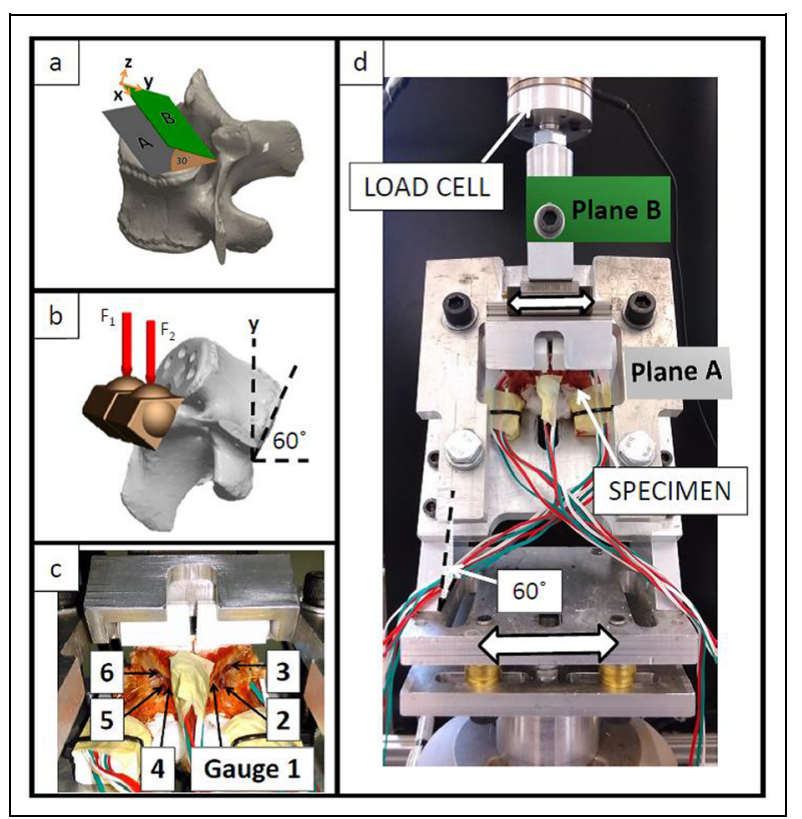

Figure 2. (a) Planes of loading through IV disc (A) and loading (B), (b) oblique view of specimen as mounted in apparatus, also showing cast PU loading domes, (c) posterior view of strain gauge locations on left and right hand laminae and (d) experimental apparatus.

pieces of facet bone. The superior end of the vertebral body and superior facets were also fixed in cast polyurethane using an identical method (Figure 2(b) and (c)).

\section{Test method}

In order to examine the response of the posterior portions of the vertebra, it was necessary to load them in isolation. The method proposed by Cyron et al. ${ }^{27}$ was adapted whereby the fully intact vertebra is mounted, cranial end down, such that the facet surfaces are loaded on a plane $30^{\circ}$ from the plane of the intravertebral (IV) disc. This plane is approximately perpendicular to the principal axis of the dorsal cortex of the pars interarticularis, therefore applying load on this plane will induce bending in this cortex (Figures 1 and 2). The vertebral body of each specimen is secured in the test rig by way of four 4-mm tapered pins top and bottom which penetrate the end plates of the vertebral body. The loads $\left(F_{1}\right.$ and $\left.F_{2}\right)$ are applied to the cast polyurethane domed surfaces on each facet (Figure 2(b)).

Test loads. Due to the effect of inter-specimen variability, the following method, similar to that used by Cristofolini et al., ${ }^{28}$ was used in order to establish a standard test load for each specimen:

- Strain data from all 18 rosette gauge elements are monitored.
- The absolute maximum of the three gauge elements associated with each rosette are recorded, irrespective of planar direction or sign (positive or negative).

- These six readings (one absolute maximum per rosette) are then averaged giving a 'general measure' of strain in the vertebral lamina.

- A load is applied to the facets and manually increased until the average strain is $1500 \mu \varepsilon$.

- That load is then recorded (Table 2).

- These same loads are applied to each specimen at offsets of zero, $+3.5,+7,-3.5$ and $-7 \mathrm{~mm}$ (five tests per specimen).

Facet angle asymmetry offsets. Figure 2(a) shows a schematic layout for the planes of loading. The predominant forces acting on the facet joints in the lower lumbar column are the sum of the force due to the upper body mass and the extensor muscles, both together called, in this case, the extensor force $(F)$. This extensor force acts on a plane ' $B$ ' oriented $30^{\circ}$ from the plane of the IV disc (plane ' $A$ '). The assumption is that this force is equally apportioned to each facet and acts normal to the surface of the facet. Since each facet surface is at a different angle, it is possible to calculate the forces on plane ' $B$ ' acting in the $\mathrm{Y}$ direction (parallel to the sagittal plane) for each facet as

$$
F_{1}=\frac{F}{2} \cos \theta_{1}
$$

and

$$
F_{2}=\frac{F}{2} \cos \theta_{2}
$$

The ratio of forces acting in direction $\mathrm{Y}$ is equal to

$$
\left(\cos \theta_{2} / \cos \theta_{1}\right)=\left(F_{2} / F_{1}\right)
$$

Degrees of facet angle asymmetry were found by measuring clinical CT scans, where the facet angle is defined as the angle (on plane ' $A$ ') between the surface of the facet and the coronal plane (Table 1). From these data, a medium level of facet angle asymmetry equal to $18^{\circ}$ difference between facets and a maximum level of facet angle asymmetry equal to $28^{\circ}$ of difference were defined. This gives maximum load ratio $\left(F_{2} /\right.$ $F_{1}$ ) of 1.75 for $18^{\circ}$ of facet angle asymmetry and 3.34 for $28^{\circ}$ of facet angle asymmetry. The test apparatus was designed such that the base could be adjusted in the transverse direction. This adjustment allows the point of loading to be displaced either left or right in order to mimic the effects of facet angle asymmetry. The actuator that applies the load to the facets was mounted on a lug and clevis assembly to facilitate rotation in plane ' $B$ ' and a linear slide bearing to allow lateral displacement (Figure 2(d)). A load cell (ATI Mini45 Force/Torque $1000 \mathrm{~N}$ ) was mounted above the lug and clevis and secured to the test machine (MTS Bionix). The maximum offset for the apparatus was 
Table I. Asymmetry values, published and patient data.

\begin{tabular}{|c|c|c|c|c|c|}
\hline Human facet tropism studies & Study year & Level & Normal facet & Asymmetric facet & Asymmetry (degrees) \\
\hline Rankine and Dickson ${ }^{9}$ & 2010 & L4/L5 & $52.0^{\circ}$ & $44.8^{\circ}$ & $7.2^{\circ}$ \\
\hline Masharawi ${ }^{26}$ & 2007 & L4/L5 & $45.5^{\circ}$ & $58.4^{\circ}$ & $12.9^{\circ}$ \\
\hline Kim et al. ${ }^{37}$ & 2013 & FEA & - & - & $5.0^{\circ}$ \\
\hline Boden $^{38}$ & 1996 & L4/L5 & - & - & $10.3^{\circ}$ \\
\hline Patient data, female, 15 years ${ }^{a}$ & 2014 & L4/L5 & $51.1^{\circ}$ & $23.0^{\circ}$ & $28.1^{\circ}$ \\
\hline Patient data, male, 12 years ${ }^{\mathrm{a}}$ & 2014 & $\mathrm{~L} 3 / \mathrm{L} 4$ & $49.0^{\circ}$ & $41.1^{\circ}$ & $7.9^{\circ}$ \\
\hline Patient data, female, 15 years ${ }^{\mathrm{a}}$ & 2014 & L4/L5 & $54.0^{\circ}$ & $70.9^{\circ}$ & $16.9^{\circ}$ \\
\hline Patient data, male, 14 years ${ }^{\mathrm{a}}$ & 2013 & L4/L5 & $57.4^{\circ}$ & $45.0^{\circ}$ & $12.4^{\circ}$ \\
\hline Patient data, female, 18 years ${ }^{\mathrm{a}}$ & 2013 & L4/L5 & $46.0^{\circ}$ & $39.8^{\circ}$ & $6.2^{\circ}$ \\
\hline Patient data, female, 13 years $^{\mathrm{a}}$ & 2013 & L4/L5 & $53.2^{\circ}$ & $71.5^{\circ}$ & $18.3^{\circ}$ \\
\hline Min. & & & & & $5.0^{\circ}$ \\
\hline Max. & & & & & $28.1^{\circ}$ \\
\hline
\end{tabular}

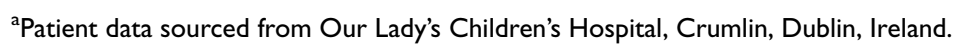

$7 \mathrm{~mm}$ giving a load ratio $\left(F_{2} / F_{1}\right)$ of 3.33 , equivalent to $28^{\circ}$ of facet angle asymmetry, an intermediate offset was also chosen at $3.5 \mathrm{~mm}$ giving a load ratio of 1.74 , equivalent to $18^{\circ}$ of facet angle asymmetry. A total of five tests for each of the 12 specimens were carried out, at zero facet angle asymmetry, $+3.5,+7,-3.5$ and $-7 \mathrm{~mm}, 60$ tests in total.

\section{Statistical methods}

The slope of the regression line calculated for all principal strain measurements was tested using a one-sample hypothesis test for correlation. The null hypothesis being that the slope of the population regression line is zero $($ alpha $=0.05)$.

\section{Results}

A set of pre-tests were carried out in order to establish the mean fatigue test load for each specimen. Table 2 presents details of the specimens used and the corresponding test loads; it should be noted that no linear predictive relationship existed for this sample set $(n=13)$ between animal mass $(\mathrm{kg})$ and test load $(\mathrm{N})$ for either the fourth lumbar level $\left(R^{2}=0.0204\right)$ or the fifth lumbar level $\left(R^{2}=0.0352\right)$. Figure 3 shows the test results for the left-hand and right-hand side laminae. Reported strain values are the average of the principal strain results for three rosette gauges and average principal strain for the vertebral lamina. As facet angle asymmetry increases, there is a commensurate increase in tensile and compressive principal strain. A strong linear trend is evident between the difference in facet angle asymmetry and the measured strain with $R^{2}>0.9$ for all results. Standard deviations fall within the range of $15 \%-18 \%$ for compressive principal strain and approximately $30 \%$ for tensile principal strain. The percentage difference in tensile and compressive principal strain (Figure 4) shows only a small increase $(5 \%-6 \%)$ at the intermediate level of facet angle asymmetry; however, this increases to almost $15 \%$ at the maximum level of
Table 2. Specimen details and corresponding test load at $1500 \mu \varepsilon$.

\begin{tabular}{llll}
\hline Specimen no. & $\begin{array}{l}\text { Spinal } \\
\text { level }\end{array}$ & $\begin{array}{l}\text { Animal } \\
\text { mass }(\mathrm{kg})\end{array}$ & $\begin{array}{l}\text { Test load }(\mathrm{N}) \\
\text { to I } 500 \mu \varepsilon\end{array}$ \\
\hline 312 & L4 & 67 & 350 \\
312 & L5 & 67 & 430 \\
313 & L4 & 65 & 400 \\
313 & L5 & 65 & 400 \\
489 & L4 & 70 & 265 \\
489 & L5 & 70 & 400 \\
491 & L4 & 70 & 470 \\
491 & L5 & 70 & 300 \\
492 & L4 & 76 & 350 \\
492 & L5 & 76 & 270 \\
493 & L4 & 85 & 300 \\
493 & L5 & 85 & 400 \\
355 (micro-CT) & L4 & 60 & 191 \\
\hline
\end{tabular}

$\mathrm{CT}$ : computed tomography.

facet angle asymmetry with little difference between the left- and right-hand side. A linear relationship exists between the difference in facet angle asymmetry and the measured strain with significant non-zero slopes for all principal strain measurements; $p$-values of 0.006 and 0.045 were calculated for principal strains $\varepsilon_{1}$ and $\varepsilon_{2}$ on the right-hand side and $p$-values of 0.009 and 0.001 for principal strains $\varepsilon_{1}$ and $\varepsilon_{2}$ on the left-hand side (Table 3).

\section{Discussion}

The experiments carried out in this study have replicated what occurs when one facet is more coronally oriented and has also measured the resulting strains in the vertebral laminae. The measurements taken suggest that, for these non-pathological loads, the relationship between load offset, or facet angle asymmetry resulting from facet orientation, and the resulting principal strains is a linear predictive relationship. The work of Shah et al. ${ }^{21}$ reported compressive principal strain values of $2400 \mu \varepsilon$ for an applied compressive load of 


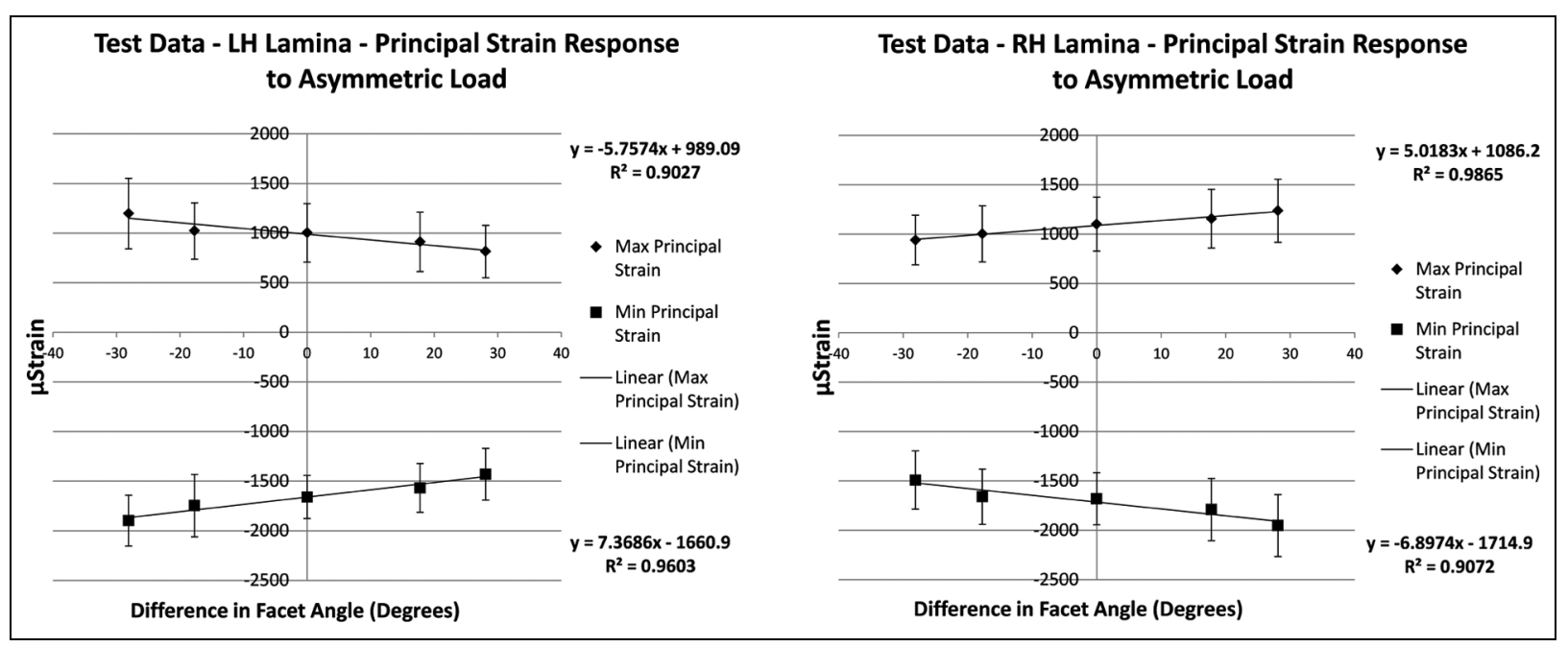

Figure 3. Test results: principal strain response to asymmetric loading of the vertebral laminae, left hand plot relates to left hand lamina as viewed in apparatus and right hand plot to right hand lamina.

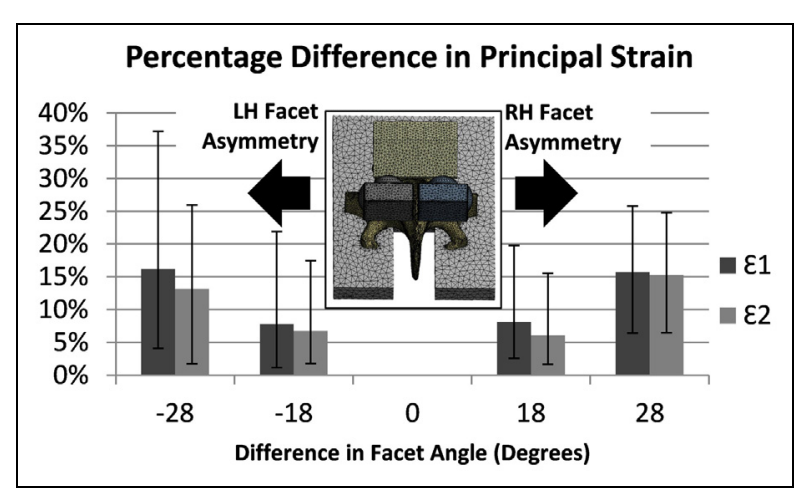

Figure 4. Average percentage difference in principal strain with increasing asymmetry offset. Inset: Plan view of specimen with load offset directions indicated.

$1471 \mathrm{~N}$. The authors applied the load to the entire FSU, disc and posterior structures. Compressive load sharing in the lumbar column is $70 / 30$ between the IV disc and facets; ${ }^{29}$ therefore, for an applied load of $1471 \mathrm{~N}$ across the entire FSU, the loading on the facets is $441.3 \mathrm{~N}$. This facet load is similar to the test loads used in this study (Table 2) and the resulting strain of $2400 \mu \varepsilon$ from the Shah et al. ${ }^{21}$ study is almost identical to the maximum compressive principal strain value recorded $2370 \mu \varepsilon$ in this study. Earlier studies such as that of Szivek et al. ${ }^{22}$ and Kuo and Wang ${ }^{23}$ have reported $1795 \mu \varepsilon$ (human, stair climbing) and $1700 \mu \varepsilon$ (porcine, spinal extension with twisting), respectively. The values recorded in this study are within a similar range, in that the strains are non-pathological, but are significant in terms of the potential stress fracture. Test load level (Table 2) was set for each specimen based on an average laminae strain level of $1500 \mu \varepsilon$ which is approximately equal to $50 \%$ of the lowest known pathological strain level, ${ }^{18}$ and it is important to note that the total applied load was not altered, simply the level apportioned to each side of the facets. The strain levels in the pars interarticularis reached an average compressive maximum of $2019 \mu \varepsilon$ ( $67 \%$ of pathological strain level) at $7 \mathrm{~mm}$ offset. The highest recorded reading was approximately $80 \%$ of pathological levels. Recorded strains at the intermediate level of facet angle asymmetry $(3.5 \mathrm{~mm})$ had an average increase of $3 \%$ increase in the negative direction and $8 \%$ increase in the positive direction. The offset of $3.5 \mathrm{~mm}$ is equivalent to approximately $18^{\circ}$ of facet asymmetry; this maximum change in strain, of just $8 \%$, indicates that atrisk individuals may fall in the group with facet angle asymmetry $>18^{\circ}$.

\section{Limitations}

The use of porcine vertebral specimens is an acceptable biomechanical surrogate for human specimens. ${ }^{30-33}$ The choice of porcine lumbar vertebrae for this study

Table 3. Significance of linear slopes.

\begin{tabular}{|c|c|c|c|c|c|c|}
\hline Position & Gauge no. & Reading & Slope ( $\mu \varepsilon /$ degree) & $Y$ intercept $(\mu \varepsilon)$ & $R^{2}$ & $p$ value \\
\hline Right & $1,2,3$ & Max. principal & 5.0 & 1086 & 0.99 & 0.006 \\
\hline Right & I, 2,3 & Min. principal & -6.9 & -1715 & 0.91 & 0.045 \\
\hline Left & $4,5,6$ & Max. principal & -5.8 & 989 & 0.90 & 0.009 \\
\hline Left & $4,5,6$ & Min. principal & 7.4 & $-|66|$ & 0.96 & 0.001 \\
\hline
\end{tabular}


was based on their comparative similarity in size to human lumbar vertebrae. It is accepted that other areas of the spine are more suitable for joint biomechanics; the porcine cervical spine displays the closest relationship to the human lumbar spine in terms of flexion and extension; ${ }^{34}$ however, it is limited in terms of lateral bending and axial rotation. ${ }^{35}$ The age of the specimens used is also noteworthy; porcine bone specimens harvested from 6-month-old animals display a transitional structure whereby the vertebrae are moving from a strength derived mainly from bone density to one derived from structural adaptation. ${ }^{36}$ The micro-CT scan obtained as part of this study (Figure 1) clearly shows the presence of growth plates in the vertebral body; however, no evidence can be observed for the growth centres in the neural arch. The trabecular structure in this region, although sparse and thick in terms of individual trabeculae, appears reasonably uniform and fits with the description of Curry's sandwich bone. ${ }^{17}$ The presence of growth plates in the vertebral body does not present a problem for this study as the entire anterior column of the vertebra is constrained in the test apparatus. This choice of test method was made in order to eliminate as many variables as possible and isolate the effect of facet coronal orientation. It is worth reiterating the similarity in pars strain observed between this study and that of Shah et al. ${ }^{21}$ in which the entire vertebra (anterior and posterior portions) was loaded; this displays that the loading regime, although simplified, produces results that are in agreement with previously published work.

\section{Conclusion}

To the authors' knowledge, this is the first study to show the linear relationship between load offset as a result of facet asymmetry and the resulting change in principal strain in the vertebral laminae. The results showed an average maximum increase of $19 \%$ in strain with one instance of strain values approaching $80 \%$ of pathological levels. Test results also suggest that individuals with $<18^{\circ}$ of facet asymmetry are at a lower risk of developing a stress fracture, with an average maximum increase in strain of $8 \%$. The final conclusion of this article is that change in principal strain as a result of facet asymmetry has a linear relationship and an asymmetry threshold exists beyond which compressive strain on the asymmetric side can be increased by up to $15 \%$.

\section{Acknowledgements}

The authors would like to thank the following people for their assistance with this study: David Connolly, Dr Stefan Lohfeld and Paul Gunning of the National University of Ireland, Galway, for their assistance with micro-CT scans and access to segmentation software; Dr Gerard Sheridan of Tallaght Hospital (AMNCH) for his assistance in sourcing the patient data; and Ms
Betty Byrne of Byrne's Butchers in Camolin, Wexford, for the free range porcine spinal specimens.

\section{Declaration of conflicting interests}

The author(s) declared no potential conflicts of interest with respect to the research, authorship and/or publication of this article.

\section{Funding}

The author(s) disclosed receipt of the following financial support for the research, authorship, and/or publication of this article: This work was funded under the Irish Research Council Embark Award Scheme, RS/ 2012/318.

\section{References}

1. Hensinger RN. Spondylolysis and spondylolisthesis in children and adolescents. J Bone Joint Surg Am 1989; 71: 1098-1107.

2. Wiltse LL. Etiology of spondylolisthesis. Clin Orthop Relat Res 1956; 10: 48-60.

3. Sutton JH, Guin PD and Theiss SM. Acute lumbar spondylolysis in intercollegiate athletes. $J$ Spinal Disord Tech 2012; 25: 422-425.

4. Brunker P, Bradshaw C, Khan KM, et al. Stress fractures: a review of 180 cases. Clin J Sport Med 1996; 6: 85-89.

5. Jackson DW. Spondylolysis in the female gymnast. Clin Orthop Relat Res 1976; 117: 68-73.

6. Swärd L, Hellström M, Jacobsson B, et al. Spondylolysis and the sacro-horizontal angle in athletes. Acta Radiol 1989; 30: 359-364.

7. Toueg C-W, Mac-Thiong J-M, Grimard G, et al. Prevalence of spondylolisthesis in a population of gymnasts. Stud Health Technol Inform 2010; 158: 132-137.

8. Beutler WJ, Fredrickson BE, Murtland A, et al. The natural history of spondylolysis and spondylolisthesis: 45year follow-up evaluation. Spine 2003; 28: 1027-1035.

9. Rankine JJ and Dickson RA. Unilateral spondylolysis and the presence of facet joint tropism. Spine 2010; 35: E1111-E11114.

10. Mente PL, Stokes IA, Spence H, et al. Progression of vertebral wedging in an asymmetrically loaded rat tail model. Spine 1997; 22: 1292-1296.

11. Stokes AF, Spence H, Aronsson DD, et al. Mechanical modulation of vertebral body growth. Spine 1996; 21: $1162-1167$.

12. Crawford CH, Ledonio CGT, Bess RS, et al. Current evidence regarding the etiology, prevalence, natural history, and prognosis of pediatric lumbar spondylolysis: a report from the Scoliosis Research Society Evidence-Based Medicine Committee. Spine Deform 2015; 3: 12-29.

13. Crewe $\mathrm{H}$. Lumbo-pelvic loading during fast bowling in adolescent cricketers: the influence of bowling speed and technique. J Sports Sci 2013; 31: 1082-1090.

14. Annear PT. Pars interarticularis stress and disc degeneration, cricket's potent strike force: the fast bowler. $A N Z J$ Surg 1992; 62: 768-773.

15. Jackson DW. Stress reactions involving the pars interarticularis in young athletes. Am J Sports Med 1981; 9: 304 312 . 
16. Hoshina H. Spondylolysis in athletes. Phys Sport Med 1980; 8: 75-79.

17. Currey JD. Comparative mechanical properties and histology of bone. Integr Comp Biol 1984; 24: 5.

18. Cowin SC (ed.). Bone mechanics handbook. 2nd ed. Boca Raton, FL: CRC Press, 2001.

19. Lanyon LE, Hampson WG, Goodship AE, et al. Bone deformation recorded in vivo from strain gauges attached to the human tibial shaft. Acta Orthop Scand 1975; 46: 256-268.

20. Grassi L and Isaksson H. Extracting accurate strain measurements in bone mechanics: a critical review of current methods. J Mech Behav Biomed Mater 2015; 50: 43-54.

21. Shah JS, Hampson WG and Jayson MI. The distribution of surface strain in the cadaveric lumbar spine. $J$ Bone Joint Surg Br 1978; 60: 246-251.

22. Szivek JA, Roberto RF and Margolis DS. In vivo strain measurements from hardware and lamina during spine fusion. J Biomed Mater Res B Appl Biomater 2005; 75: 243-250.

23. Kuo Y and Wang J. Strain analysis of pars interarticularis and its implications in the spondylolysis stress fracture. Biomed Eng Appl Basis Commun 2007; 19: 79-84.

24. Carter DR, Blenman BR and Beaupré GS. Correlations between mechanical stress history and tissue differentiation in initial fracture healing. J Orthop Res 1988; 6: 736 748.

25. Frost HM. On our age-related bone loss: insights from a new paradigm. J Bone Miner Res 1997; 12: 1539-1546.

26. Masharawi YM. Lumbar facet orientation in spondylolysis: a skeletal study. Spine 2007; 32: E176-E180.

27. Cyron BM, Hutton WC and Troup JDJ. Spondylolytic Fractures. J Bone Joint Surg Br 1976; 58: 462-466.

28. Cristofolini L, Brandolini N, Danesi V, et al. Strain distribution in the lumbar vertebrae under different loading configurations. Spine J 13: 1281-1292.

29. Panjabi MM, Oxland TR and Yamamoto I. Mechanical behaviour of the human lumber and lumbosacral spine as shown by three-dimensional load-displacement curves. J Bone Joint Surg Am 1994; 76: 413-424.

30. Busscher I, van der Veen AJ, van Dieën JH, et al. In vitro biomechanical characteristics of the spine: a comparison between human and porcine spinal segments. Spine 2010; 35: E35-E42.

31. Dath R, Ebinesan AD, Porter KM, et al. Anatomical measurements of porcine lumbar vertebrae. Clin Biomech 2007; 22: 607-613.

32. Dickey JP, Dumas GA, Bednar DA, et al. Comparison of porcine and human lumbar spine flexion mechanics. Vet Comp Orthop Traumatol 2003; 16: 44-49.

33. Van Dieën JH, van der, Veen A, van Royen BJ, et al. Fatigue failure in shear loading of porcine lumbar spine segments. Spine 2006; 31: E494-498.

34. Wilke H-J, Geppert $\mathbf{J}$ and Kienle A. Biomechanical in vitro evaluation of the complete porcine spine in comparison with data of the human spine. Eur Spine $J$ 2011; 20: 1859-1868.

35. Schmidt R, Richter M, Claes L, et al. Limitations of the cervical porcine spine in evaluating spinal implants in comparison with human cervical spinal segments: a biomechanical in vitro comparison of porcine and human cervical spine specimens with different instrumentation techniques. Spine 2005; 30: 1275-1282.

36. Tanck E, Homminga $\mathrm{J}$, van Lenthe $\mathrm{GH}$, et al. Increase in bone volume fraction precedes architectural adaptation in growing bone. Bone 2001; 28: 650-654.

37. Kim H-J, Chun H-J, Lee H-M, et al. The biomechanical influence of the facet joint orientation and the facet tropism in the lumbar spine. Spine J 13: 1301-1308, http:// www.ncbi.nlm.nih.gov/pubmed/24035730 (2013, accessed 23 September 2013).

38. Boden S, Riew K and Yamaguchi K. Orientation of the lumbar facet joints: association with degenerative disc disease. J Bone Jt Surg Am 1996; 78: 403-411. 